\title{
ENERGY AND THE ENVIRONMENT \\ IN THE 21ST CENTURY
}

\author{
Dr. Arnulf Grübler \\ and \\ Dr. Nebojša Nakićenović
}

Environmentally Compatible Energy Strategies

International Institute for Applied Systems Analysis A-2361 Laxenburg, Austria 



\section{Background}

Energy-related emissions of greenhouse gases (GHGs) - and especially of carbon dioxide $\left(\mathrm{CO}_{2}\right)$ - are an important cause of increasing concerns over global environmental changeconcerns that reflect a growing search for longer-term environmental security and sustainability of human development, both in the energy community, in policy circles and among the public at large. After nearly 20 years of many global, regional and national energy studies, perceptions of the major driving forces of the future evolution of the energy system have changed. Concerns about physical and economic availability of adequate energy resources have given way to increasing awareness of global and long-term environmental impacts of energy production, conversion and end-use.

Today, the predominant question is whether it would actually be possible to continue consuming fossil energy at current or even higher rates in the future. What is new is that instead of energy resources the risks of adverse global change could constitute the ultimate limit of future development in energy systems. Thus, the ultimate global resource could be the environment rather than recoverable energy reserves and resources.

Since the onset of the Industrial Revolution, humanity has consumed fossil energy amounting to some $200 \mathrm{Gt}$ carbon and current annual emissions from fossil energy use amount to almost $6 \mathrm{Gt}$ carbon (C). Compared to this, our remaining "carbon wealth" accumulated over geological times is orders of magnitudes higher. Currently identified, economically recoverable energy reserves amount to $540 \mathrm{Gt} \mathrm{C}$ (Table 1). Additional $3026 \mathrm{Gt} \mathrm{C}$ are contained in resources (i.e., identified quantities, whose economic recoverability is uncertain at present) and further $5200 \mathrm{Gt} \mathrm{C}$ are contained in additional occurrences (quantities inferred by broad geological information but with their economic and technical potentials remaining largely speculative). Remaining fossil energy resources thus range between 3500 to $8700 \mathrm{Gt}$ carbon, compared to a current atmospheric carbon loading of about 760 Gt. This clearly illustrates that already currently known fossil energy sources could be sufficiently large to raise atmospheric $\mathrm{CO}_{2}$ concentrations by several factors.

In order to assess possible and likely future trends in the energy sector, Stanford University and IIASA have been jointly organizing since 1981 the International Energy Workshop (IEW) with the aim to compare energy projections made by different groups in the world and to analyze their differences. The median of global $\mathrm{CO}_{2}$ emissions calculated from the IEW polls of global energy consumption or, in our interpretation, the current "consensus view" of the future, corresponds to an annual growth rate of one percent per year, i.e., to an increase from about $6 \mathrm{Gt}$ today to some $9 \mathrm{Gt}$ carbon by the year 2020, with a range between 8 to $10 \mathrm{Gt}$ as shown in Figure 1. Although lower than the "business-as-usual" scenario of the IPCC for the same year, the IEW poll range gives rise to concerns as to how such a trend could be "bent" downwards, e.g., along the lines of the Low Emission and Accelerated Policy scenarios of the IPCC. All this suggests that-in the absence of appropriate countermeasures-global carbon emissions will rise, perhaps beyond environmentally acceptable levels.

Thus, perceptions about factors ultimately limiting future energy growth have changed, while the driving forces are still the same-population and economic growth. Some of the measures and strategies that seemed to be desirable in the past, however, appear to be invariant to this shift in perceptions. Efficiency improvements and conservation are instrumental in reducing both fossil fuel requirements and emissions. 


\section{Objectives of the IIASA Activities}

The objective of the IIASA study is to develop an analytical framework to evaluate policy options and future global energy strategies directed at delaying or mitigating global change. In particular, the objective is to assess future potentials and rates of reducing energy and carbon intensity worldwide. Figure $\mathbf{2}$ shows historical improvements toward improving energy efficiency and decarbonization in a number of selected countries. The aim is to analyze future trajectories that would lead individual countries and the world as a whole further toward the origin of Figure 2. The purpose is to analyze global tradeoffs involved in ecology and climatic change, technology and economic development, social conditions and lifestyles, and international interactions as reflected in negotiations on how to distribute the burdens and benefits.

The project is developing a comprehensive assessment of a broad range of options (technologies, associated economic incentives and institutional frameworks for their implementation) that is needed for evaluating the global potential for stabilizing, ultimately reducing and perhaps even removing carbon dioxide and other greenhouse gases from the atmosphere. Such a system approach in assessing the contribution of individual technologies could lead to a better understanding of the aggregate potential in reducing emissions of greenhouse gases in the future. An important part of that work involves the development of an inventory of technologies for reducing carbon dioxide emissions. This inventory will provide information about technical characteristics of technologies, their cost structure and economics, and environmental profiles such as specific emissions. A special feature of this inventory is that it will also specify the applicability of mitigation technologies in different technological, economic or cultural settings, and will specify the time horizon of their availability and their forward and backward linkages to other enabling technologies in the energy system.

The second objective is to identify constraints and boundary conditions of strategies for achieving environmentally compatible paths of economic and social development. The development strategies will outline different paths of techno-economic, socio-behavioral and institutional adjustments reflecting differing technological, economic and cultural characteristics of industrial market economies, transforming economies and developing countries. Figure 3 illustrates the high degree of heterogeneity in the world today with respect to the level of energy-related $\mathrm{CO}_{2}$ emissions. It compares per capita $\mathrm{CO}_{2}$ emission for different countries indicating varying characteristics of energy systems, structure of the economy and different social and cultural settings. For example, both the USA and the area of former GDR have the highest per capita $\mathrm{CO}_{2}$ emissions in the world in excess of $5 \mathrm{t}$ carbon per year but for fundamentally different reasons. At similar levels of affluence, some other West European countries and Japan emit much less carbon indicating that decarbonization and development are not mutually exclusive provided an appropriate policy mix is found. Also striking is the strong North-South division in energy related carbon emissions, which becomes even accentuated when considering the differences in historical contributions to atmospheric concentration increases. 


\section{Inventory of Mitigation Measures}

Policy options and measures for environmentally compatible development, particularly in energy, encompass a wide range of techno-economic and socio-behavioral adjustments and responses. There is a need for a comprehensive evaluation of innovative technologies with an account of their current status, implementation prospects, applicability in different geographical, economic and cultural settings, transfer to developing countries, cost structure, technical performance, market potential, time horizons of their availability and their forward and backward linkages to other enabling technologies. Such an assessment could be used to produce an inventory of the full range of technological and economic measures spanning efficiency improvements, conservation, enhanced use of low-carbon fuels, carbon free sources of energy and other options such as afforestation and enhancement of carbon sinks.

The analysis covers the whole energy system from primary energy to actual energy services including various conversion, transport, distribution and end-use systems. The coverage of the whole energy system is important for assessing the overall mitigation potential and possibilities. For example, energy end-use is the least efficient part of current energy systems so that it becomes of crucial importance to include end-use technologies that provide transport, industrial or residential energy needs into the mitigation assessment. A detailed energy/exergy efficiency assessment of the OECD countries shows that the conversion from primary energy to final energy forms required by the consumer is about 70 percent. In contrast, the efficiency with which final energy forms are applied to provide useful energy forms and services is much lower resulting in an overall conversion efficiency of not much more than 10 percent. In developing countries and reforming economies in Europe, the overall systems energy efficiency is even lower. The efficiency of the system is still lower if different "quality" characteristics of various energy carriers and delivered forms are taken into account. Figure 4 shows that the overall exergy (second law) efficiency in the OECD countries is at most a few percent compared with the theoretical maximum. This shows that there is large scope for more efficient energy use and in particular for improvement of end-use technologies. The inventory of mitigation measures and the technology data base are specifically designed to integrate current and possible future individual conversion, transport, distribution and end-use systems into energy (or exergy) chains giving whole bundles of technologies that define a particular reduction strategy.

The overall energy efficiency of the OECD countries would be nearly doubled by application of the most efficient technologies available today. The data base will serve to assess such potential with greater consistency worldwide. The rates at which such efficiency improvements can be achieved are to a large extent dependent on the age distribution of the capital stock of our economies, rates of diffusion of new technologies and technology transfer. The long-term improvement in energy intensity of GDP was about one percent per year in the industrialized countries. However, this is a historical average over 200 years containing periods of more rapid improvement ( 2 to 3 percent per year), but also periods of stagnation and even reversals with increasing energy intensity as is the case today in a number of developing countries. Efficiency improvements have been faster in certain areas than in others. For example, over the past twenty years, aircraft manufacturers have managed to improve energy efficiency of commercial jet transports by 3 to 4 percent annually. In electricity generation, this improvement has been 2.5 to 3 percent 
per year over the period between 1930 and the late 1970s. These are about the upper boundary values to be expected in efficiency improvements in the medium term. With an improvement in the energy intensity of 3 percent per year, a dollar of GDP could be produced fifty years from now with only 20 percent of current energy requirements; this figure would be lower in terms of carbon emissions if energy substitution is also taken into account.

While efficiency improvements are a fundamental measure for reducing carbon emissions especially in the near to medium term, in the long run there is a clear need to shift to energy sources with low carbon content such as natural gas, and ultimately to those without carbon whatsoever, such as hydro, solar, and nuclear energy, and the sustainable use of biomass. Increased reliance on natural gas is a particular interesting transitional option, especially in combination with active $\mathrm{CO}_{2}$ recovery (e.g., from steam reforming). Thus, both technological and economic structural change will be of fundamental importance for improvement of efficiency and lowering of carbon emissions in order to achieve environmentally compatible pathways of socio-economic development.

\section{References}

Ausubel, J.H., Grübler, A., and Nakićenović, N., 1988, Carbon dioxide emissions in a methane economy, Climatic Change 12: 245-263.

Fujii, Y., 1990, An Assessment of the Responsibility for the Increase in the $\mathrm{CO}_{2}$ Concentration and Inter-generational Carbon Accounts, WP-90-55, International Institute for Applied Systems Analysis, Laxenburg, Austria.

Grubb, M. et al., 1991, Energy Policies and the Greenhouse Effect. Vol. II: Country Studies and Technical Options, Royal Institute of International Affairs, Dartmouth.

Grübler, A., 1989, Langfristaussichten der Energieversorgung und die potentielle Rolle von Erdgas, Gas-Wasser-Abwasser 12:763-777.

Grübler, A. and Nakićenović, 1991, Evolution of Transport Systems: Past and Future, RR-91-9, International Institute for Applied Systems Analysis, Laxenburg, Austria.

Kaya, Y., Fujii, Y., Matsuhashi, R., Yamaji, K., Shindo, Y., Saiki, H., Furugaki, I., and Kobayashi, O., 1991, Assessment of Technological Options for Mitigating Global Warming, Paper presented at the meeting of EIS Subgroup, Working Group 3 of IPCC, 6-7 August 1991, Geneva.

Marchetti, C., 1989, How to solve the $\mathrm{CO}_{2}$ problem without tears, International Journal of Hydrogen Energy 14(8): 493-506.

Nakićenović, N., Bodda, L., Grübler, A., and Gilli, P.-V., 1990, Technological Progress, Structural Change and Efficient Energy Use: Trends Worldwide and in Austria, International part of a study supported by the Österreichische Elektrizitätswirtschaft AG, IIASA, Laxenburg, Austria.

Office of Technology Assessment (OTA), 1991, Changing by Degrees: Steps to Reduce Greenhouse Gases, OTA-0-482, US Congress, OTA, Washington, D.C.

US National Academy of Sciences, 1991, Policy Implications of Greenhouse Warming: Report of the Mitigation Panel, 0-309-04545-2, National Academy Press, Washington, D.C. 


\section{Fossil Energy Consumption, Reserves and Resources (Gt C)}

\begin{tabular}{|lrrrr|}
\hline & Coal & \multicolumn{1}{c}{ Oil } & Gas & Total \\
\hline $1860-1987$ & 114.9 & 58.2 & 24.5 & 197.6 \\
1987 & 2.5 & 2.4 & 1.0 & 5.9 \\
Reserves & 391.6 & 92.1 & 58.5 & 542.2 \\
Resources & 2289 & 622 & $>115$ & 3026 \\
Additional Occurrences & $>3500$ & $>1000$ & $>700$ & $>5200$ \\
\hline
\end{tabular}

Table 1. Accounting for historical, present and potential future carbon emissions from fossil fuel use in Gigatons carbon. Historical (1860-1987) and present (1987) carbon emissions from fossil fuel use by source and carbon content in identified, economically recoverable fossil fuel reserves, resources (identified quantities with uncertain prospects of economic recoverability), and additional occurrences (additional quantities inferred from geological information but with speculative technical and economic potential). Compared to historical fossil fuel use, the remaining resources in the ground represent a (perhaps even far to large) "carbon wealth" which is more than a factor 10 as large as the total carbon pool in the atmosphere of around $760 \mathrm{Gt} \mathrm{C}$ (corresponding to a present $\mathrm{CO}_{2}$ concentration rate of about $350 \mathrm{ppm})$. 


\section{GLOBAL ENERGY-RELATED $\mathrm{CO}_{2}$ EMISSIONS}

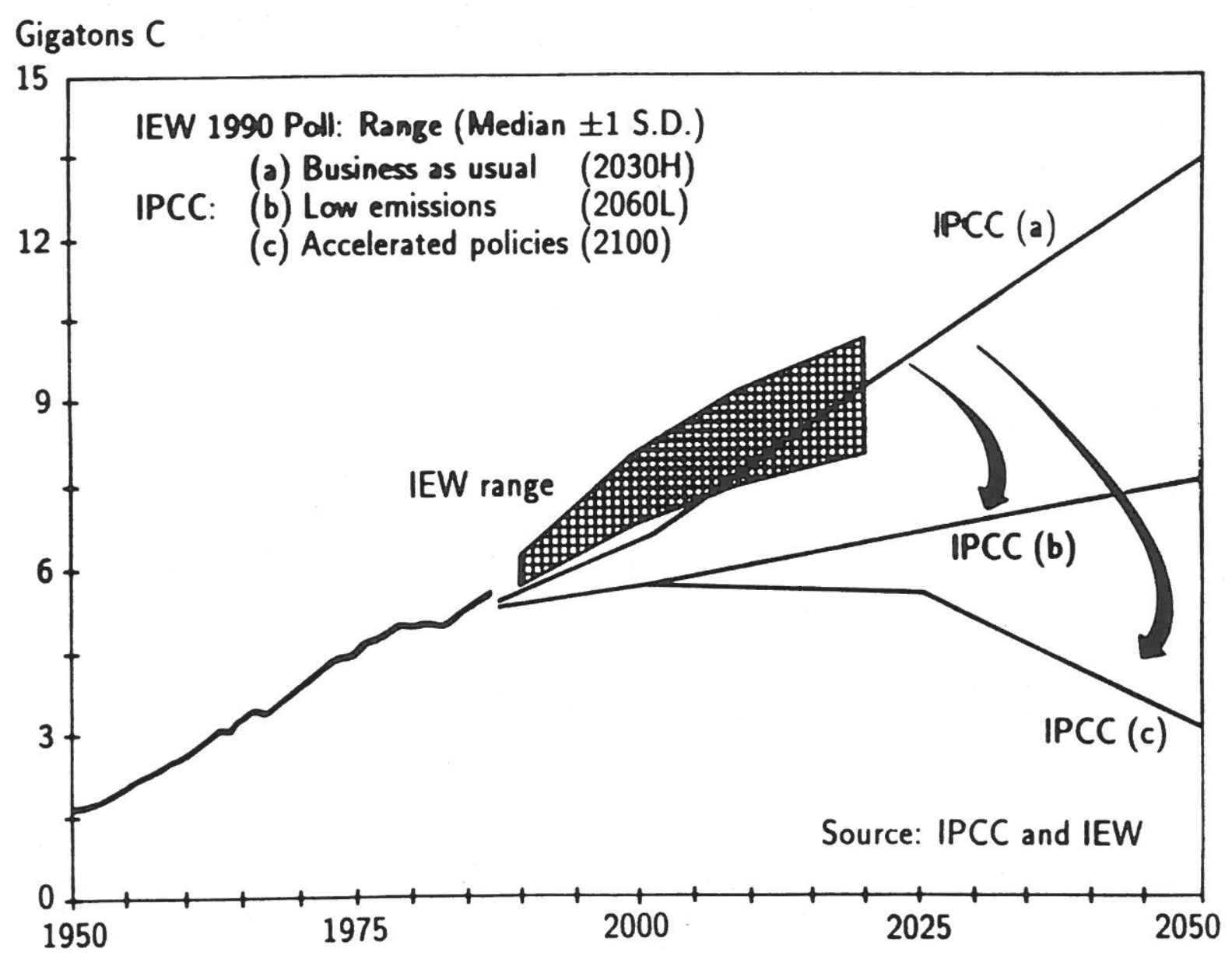

Figure 1. Historical and future global energy-related $\mathrm{CO}_{2}$ emissions. From 1950 to present emissions have increased on average at about two percent per year. Possible future global energy-related $\mathrm{CO}_{2}$ emissions are indicated by the International Energy Workshop (IEW) poll-response range and by three Intergovernmental Panel on Climate Change (IPCC) scenarios. IEW is jointly organized by Stanford University and IIASA with the aim to compare energy projections made by different groups in the world and to analyze their differences. 


\section{ENERGY EFFICIENCY AND DECARBONIZATION}

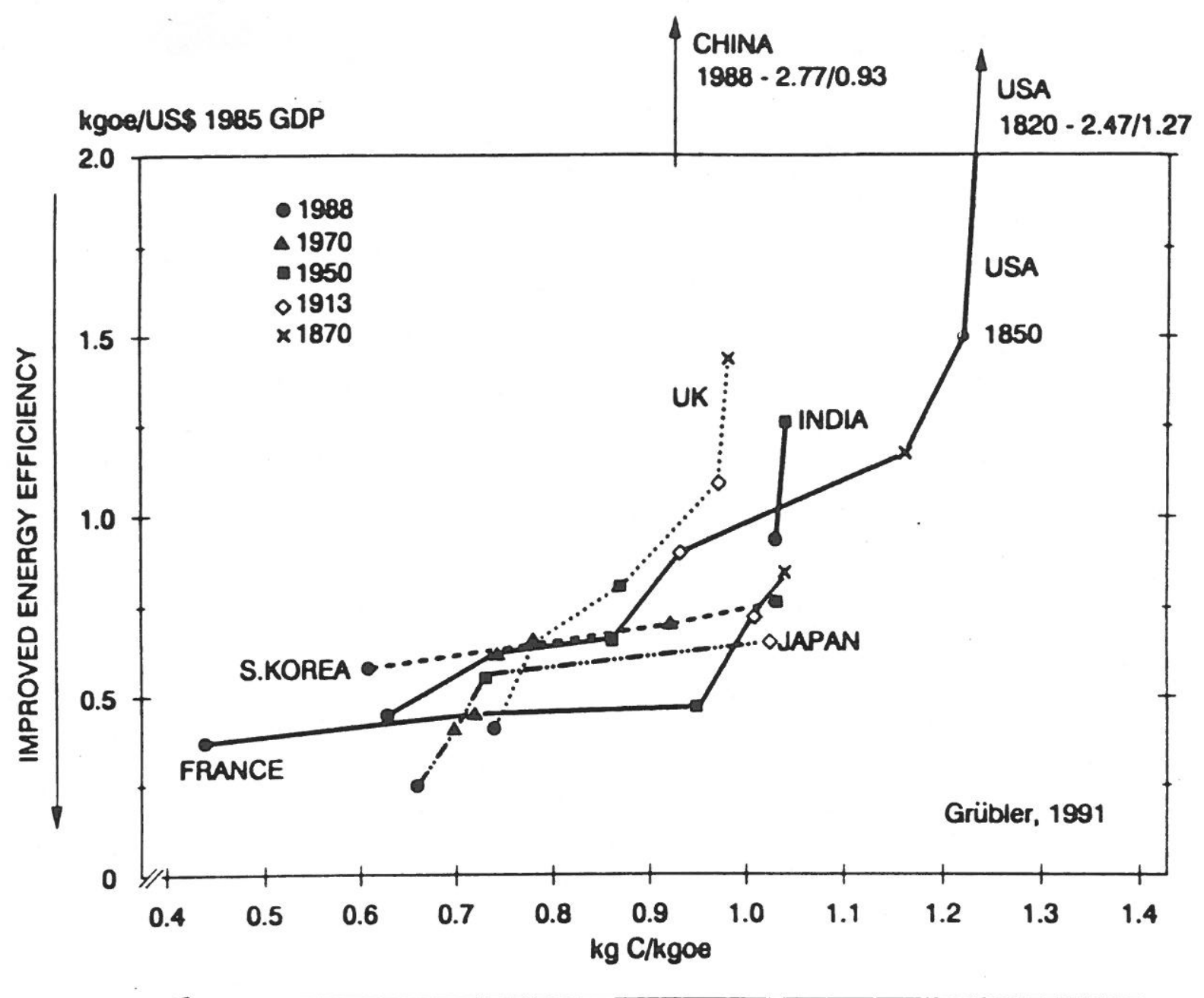

DECARBONIZATION OF ENERGY

Figure 2. Historical trends in energy (kgoe per $1000 \$$ GDP) and carbon intensity (kg C per kgoe) of various countries. Improved energy efficiency (lowering the energy intensity) and interfuel substitution (lowering the carbon intensity of energy use) are two important options for lowering overall carbon emissions. The graph shows the diverse policy mix and strategies followed in different countries over the time horizon considered. France appears to follow a decarbonization strategy, whereas Japan mostly an efficiency improvement strategy. All countries shown achieved improvements in both domains. The objective of research at IIASA in the area of Energy Climate Interactions is to assess the conditions that would direct the future development trajectories of most countries further toward the origin of this figure. 


\section{$\mathrm{CO}_{2}$ EMISSIONS PER CAPITA}

from commercial energy use in 1986

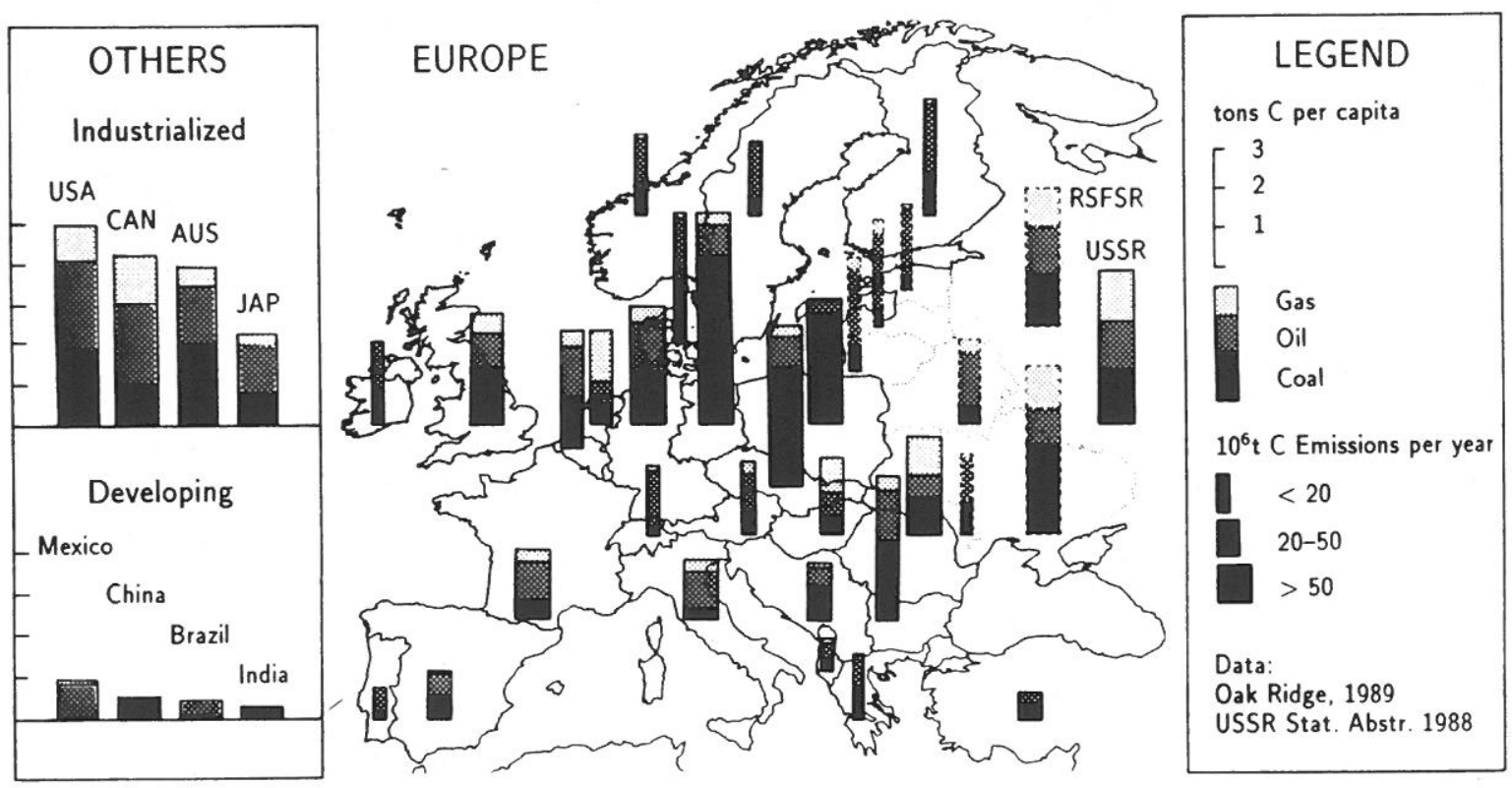

Figure 3. Per capita $\mathrm{CO}_{2}$ emissions from commercial energy use, by source and for selected countries (in tons carbon per year per capita). A graphical representation of per capita carbon emissions from energy use reveals extreme disparities and heterogeneity. These are the result of differences in degree of economic development, level and efficiency of energy consumption and the structure of the energy supply system (i.e., its carbon intensity). The figure illustrates vividly the significant North-South divide in energy related $\mathrm{CO}_{2}$ emissions. Also noticeable are the high per capita emission levels in Eastern Europe, most of them stemming from coal use. Even in cases when per capita emissions are of similar magnitude, they are often so for entirely different reasons. For example, both the USA and the former GDR have per capita $\mathrm{CO}_{2}$ emissions in excess of 5 tons carbon per year per capita. In the case of the USA this is due to high energy consumption and energy intensive lifestyles, like the high oil consumption for private transportation. In the former GDR it is due to a different level and structure of consumption and supply of energy, stressing the basic material production sector and a high share of brown coal in the energy balance. 
OECD EXERGY EFFICIENCY, 1986.

IN PERCENT OF PRIMARY EXERGY

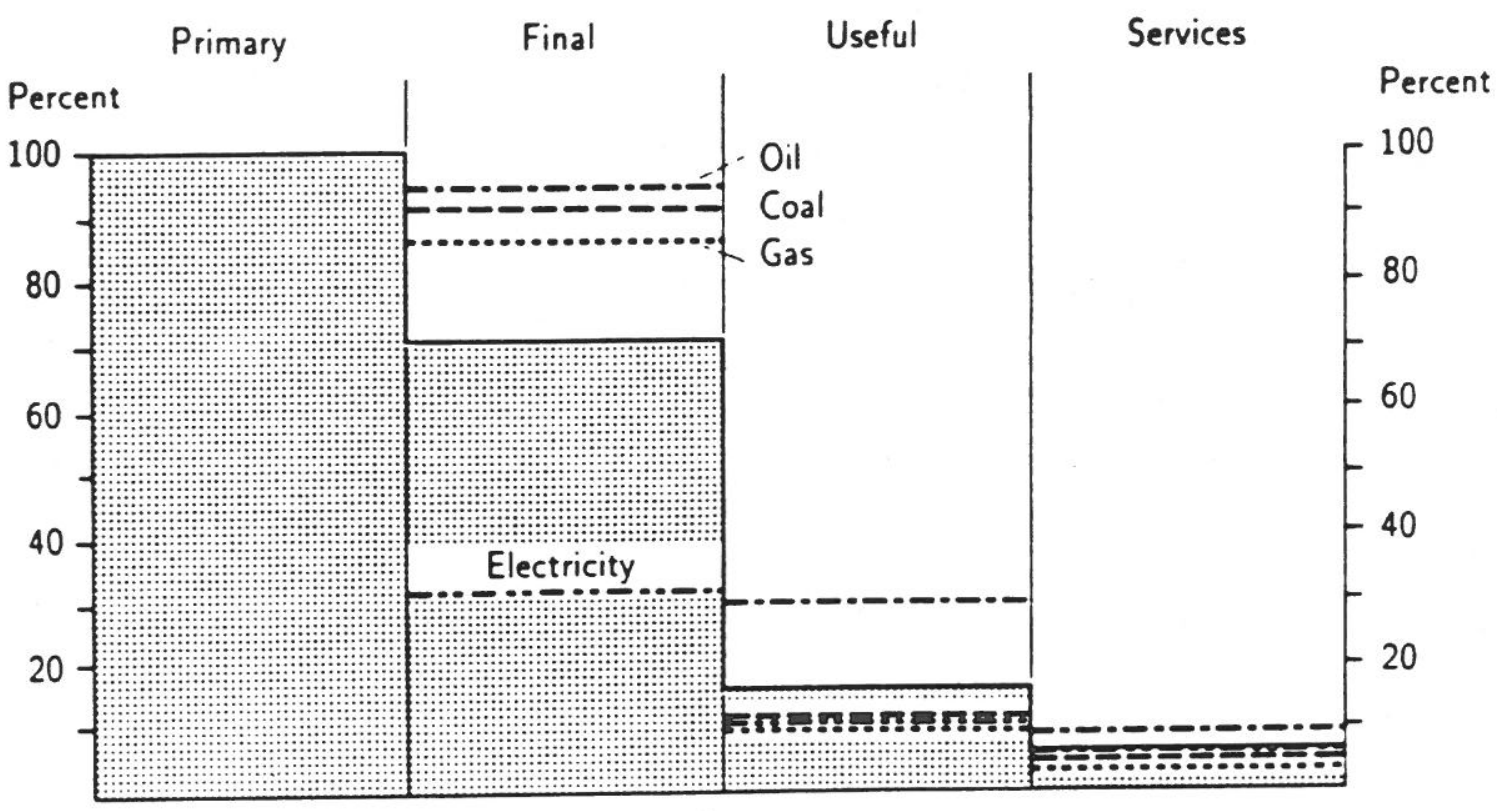

Figure 4. Exergy balances for the OECD countries in 1986 (in percent of primary exergy). A second-law analysis of the exergetic efficiency of the exergy (and energy) system in the OECD countries, shows that while the efficiency in the provision of final exergy is already quite high, efficiencies at the end-use side, and in particular in the provision of services are low. The overall exergetic efficiency of the OECD countries is estimated to among only to a few percent. Figures for the USSR and developing countries are probably even lower. This indicates the large theoretical potential for efficiency improvements of between a factor 20 to 100 . Realization of this potential depends on the implementation of many technological options and organizational innovations. Their different tradeoffs, the cost and timing involved need detailed study. 


\section{Fossil Energy Consumption, Reserves and Resources (Gt C)}

\begin{tabular}{|lrrrr|}
\hline & Coal & \multicolumn{1}{c}{ Oil } & Gas & Total \\
\hline $1860-1987$ & 114.9 & 58.2 & 24.5 & 197.6 \\
1987 & 2.5 & 2.4 & 1.0 & 5.9 \\
Reserves & 391.6 & 92.1 & 58.5 & 542.2 \\
Resources & 2289 & 622 & $>115$ & 3026 \\
Additional Occurrences & $>3500$ & $>1000$ & $>700$ & $>5200$ \\
\hline
\end{tabular}

Table 1. Accounting for historical, present and potential future carbon emissions from fossil fuel use in Gigatons carbon. Historical (1860-1987) and present (1987) carbon emissions from fossil fuel use by source and carbon content in identified, economically recoverable fossil fuel reserves, resources (identified quantities with uncertain prospects of economic recoverability), and additional occurrences (additional quantities inferred from geological information but with speculative technical and economic potential). Compared to historical fossil fuel use, the remaining resources in the ground represent a (perhaps even far to large) "carbon wealth" which is more than a factor 10 as large as the total carbon pool in the atmosphere of around $760 \mathrm{Gt} \mathrm{C}$ (corresponding to a present $\mathrm{CO}_{2}$ concentration rate of about $350 \mathrm{ppm})$. 


\section{GLOBAL ENERGY-RELATED $\mathrm{CO}_{2}$ EMISSIONS}

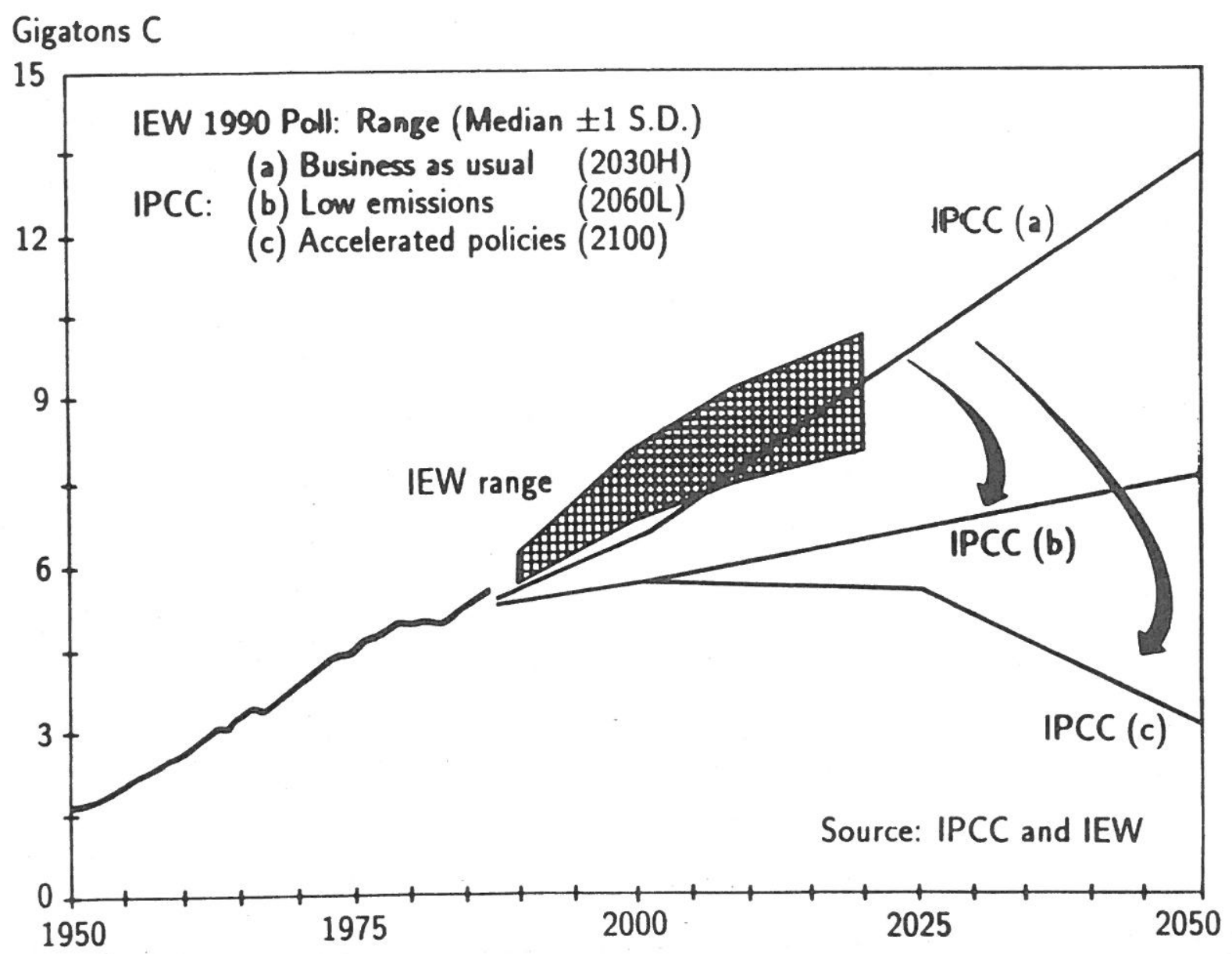

Figure 1. Historical and future global energy-related $\mathrm{CO}_{2}$ emissions. From 1950 to present emissions have increased on average at about two percent per year. Possible future global energy-related $\mathrm{CO}_{2}$ emissions are indicated by the International Energy Workshop (IEW) poll-response range and by three Intergovernmental Panel on Climate Change (IPCC) scenarios. IEW is jointly organized by Stanford University and IIASA with the aim to compare energy projections made by different groups in the world and to analyze their differences. 


\section{ENERGY EFFICIENCY AND DECARBONIZATION}

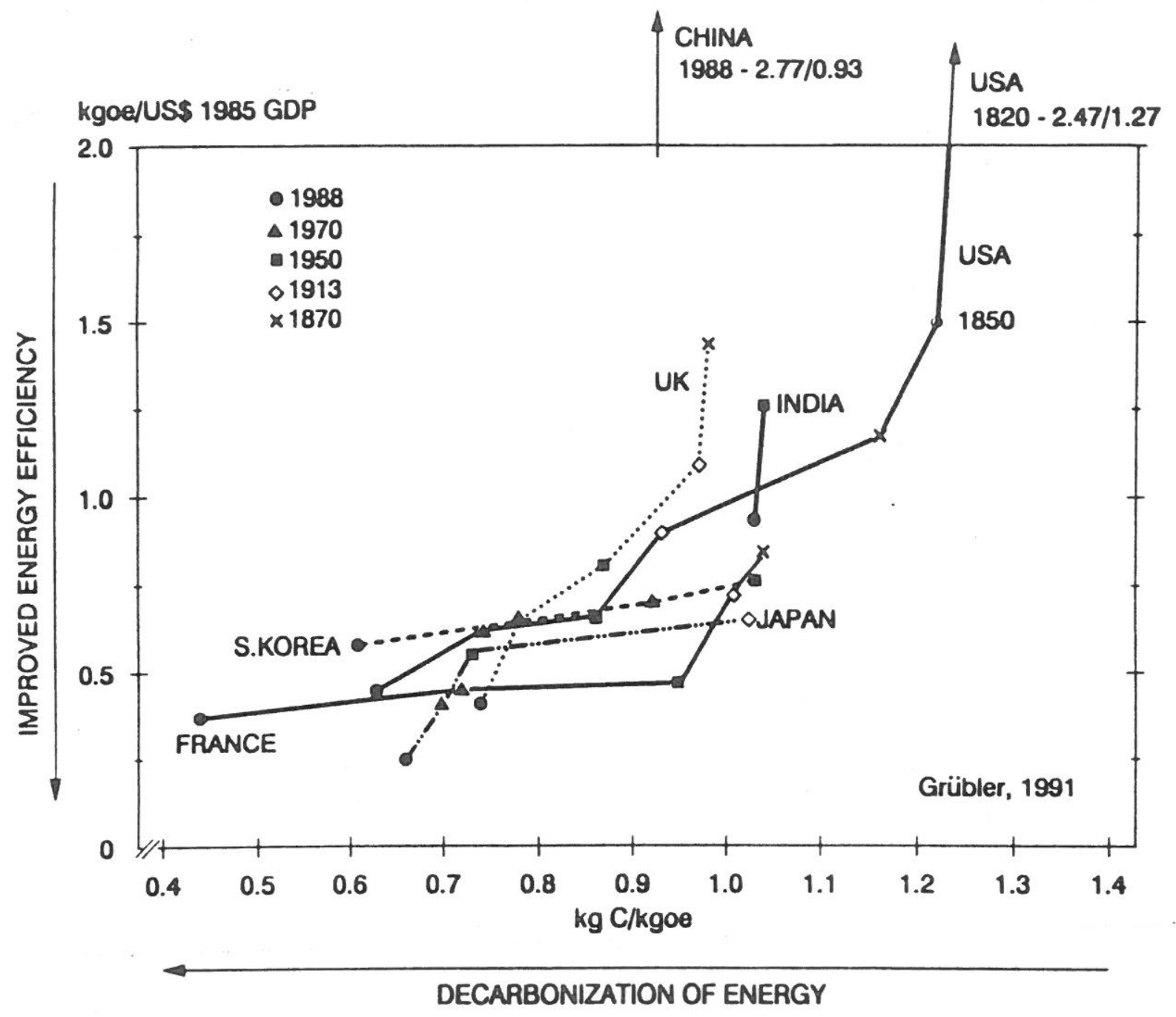

Figure 2. Historical trends in energy (kgoe per $1000 \$$ GDP) and carbon intensity (kg C per kgoe) of various countries. Improved energy efficiency (lowering the energy intensity) and interfuel substitution (lowering the carbon intensity of energy use) are two important options for lowering overall carbon emissions. The graph shows the diverse policy mix and strategies followed in different countries over the time horizon considered. France appears to follow a decarbonization strategy, whereas Japan mostly an efficiency improvement strategy. All countries shown achieved improvements in both domains. The objective of research at IIASA in the area of Energy Climate Interactions is to assess the conditions that would direct the future development trajectories of most countries further toward the origin of this figure. 


\section{$\mathrm{CO}_{2}$ EMISSIONS PER CAPITA}

from commercial energy use in 1986

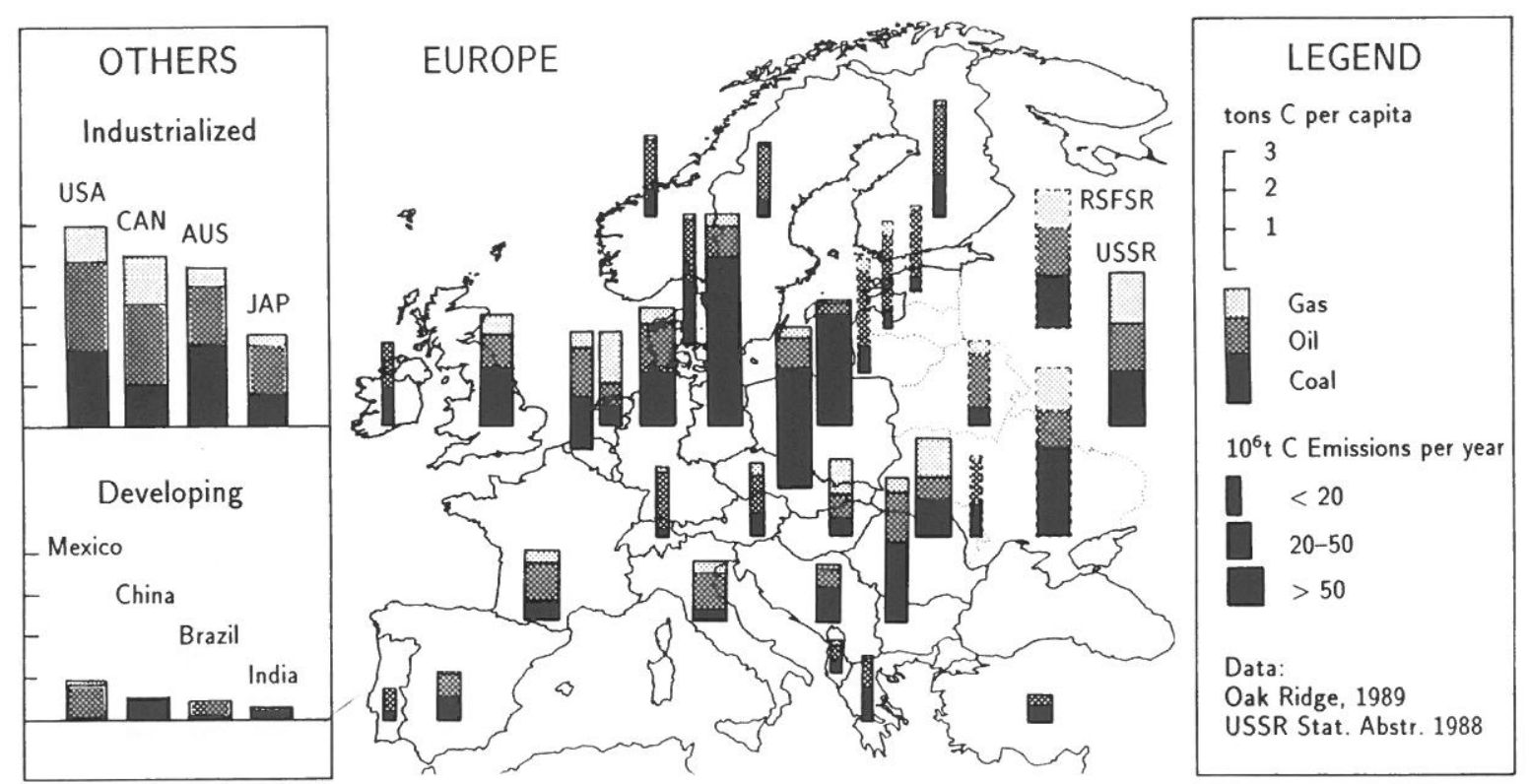

Figure 3. Per capita $\mathrm{CO}_{2}$ emissions from commercial energy use, by source and for selected countries (in tons carbon per year per capita). A graphical representation of per capita carbon emissions from energy use reveals extreme disparities and heterogeneity. These are the result of differences in degree of economic development, level and efficiency of energy consumption and the structure of the energy supply system (i.e., its carbon intensity). The figure illustrates vividly the significant North-South divide in energy related $\mathrm{CO}_{2}$ emissions. Also noticeable are the high per capita emission levels in Eastern Europe, most of them stemming from coal use. Even in cases when per capita emissions are of similar magnitude, they are often so for entirely different reasons. For example, both the USA and the former GDR have per capita $\mathrm{CO}_{2}$ emissions in excess of 5 tons carbon per year per capita. In the case of the USA this is due to high energy consumption and energy intensive lifestyles, like the high oil consumption for private transportation. In the former GDR it is due to a different level and structure of consumption and supply of energy, stressing the basic material production sector and a high share of brown coal in the energy balance. 
OECD EXERGY EFFICIENCY, 1986.

IN PERCENT OF PRIMARY EXERGY

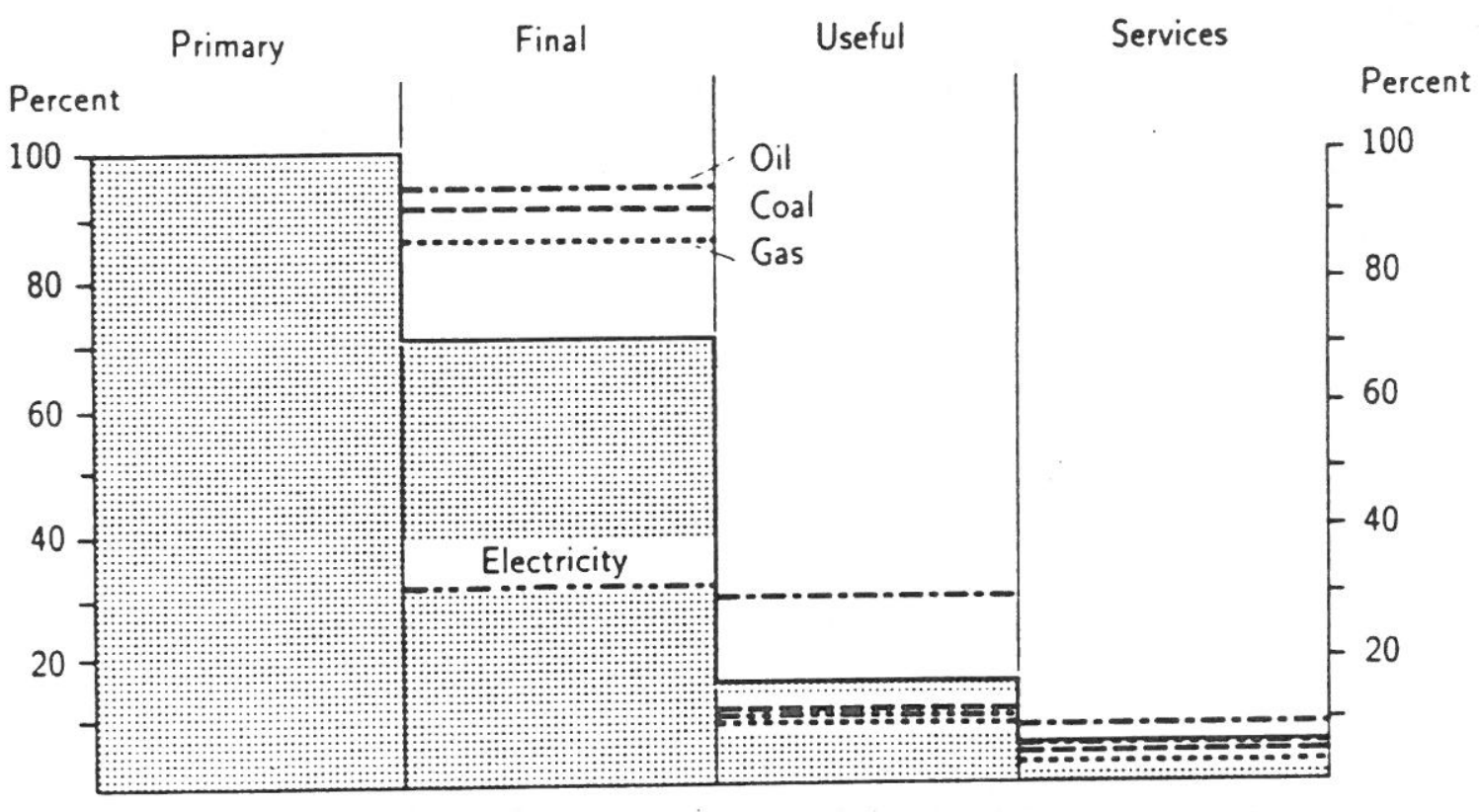

Figure 4. Exergy balances for the OECD countries in 1986 (in percent of primary exergy). A second-law analysis of the exergetic efficiency of the exergy (and energy) system in the OECD countries, shows that while the efficiency in the provision of final exergy is already quite high, efficiencies at the end-use side, and in particular in the provision of services are low. The overall exergetic efficiency of the OECD countries is estimated to among only to a few percent. Figures for the USSR and developing countries are probably even lower. This indicates the large theoretical potential for efficiency improvements of between a factor 20 to 100 . Realization of this potential depends on the implementation of many technological options and organizational innovations. Their different tradeoffs, the cost and timing involved need detailed study. 